\title{
At least three-quarters of climate change is man-made
}

\author{
Independent study quantifies human influence on global warming.
}

\section{Quirin Schiermeier}

04 December 2011

Natural climate variability is extremely unlikely to have contributed more than about one-quarter of the temperature rise observed in the past 60 years, reports a pair of Swiss climate modellers in a paper published online today. Most of the observed warming - at least 74 $\%$ - is almost certainly due to human activity, they write in Nature Geoscience ${ }^{1}$.

Since 1950 , the average global surface air temperature has increased by more than $0.5^{\circ} \mathrm{C}$. To separate human and natural causes of warming, the researchers analysed changes in the balance of heat energy entering and leaving Earth — a new 'attribution' method for understanding the physical causes of climate change.

Their findings, which are strikingly similar to results produced by other attribution methods, provide an alternative line of evidence that greenhouse gases, and in particular carbon dioxide, are by far the main culprit of recent global warming. The massive increase of atmospheric $\mathrm{CO}_{2}$ concentrations since pre-industrial times would, in fact, have caused substantially more surface warming were it not for the cooling effects of atmospheric aerosols such as black carbon, they report.

Previous attempts to disentangle anthropogenic and natural warming used a statistically complex technique called optimal fingerprinting to compare observed patterns of surface air temperature over time with the modelled climate response to greenhouse gases, solar radiation and aerosols from volcanoes and other sources.

"Optimal fingerprinting is a powerful technique, but to most people it's a black box,"

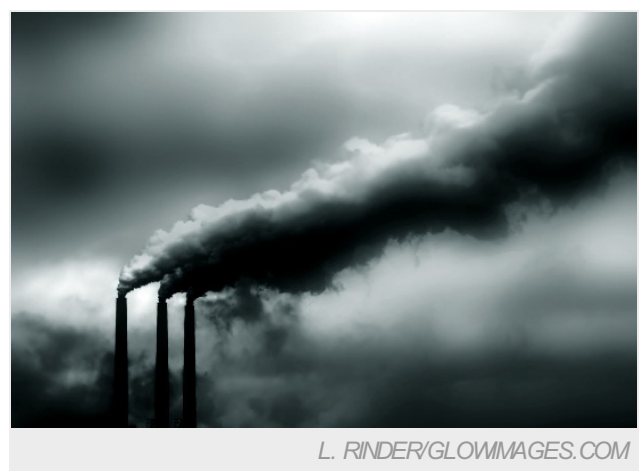

Greenhouse gases such as carbon dioxide have contributed around $0.85^{\circ} \mathrm{C}$ to global warming since the 1950s, Swiss researchers have found. says Reto Knutti, a climate scientist at the Swiss Federal Institute of Technology (ETH) in Zurich, one of the authors of the report.

\begin{abstract}
A balanced view
Knutti and his co-author Markus Huber, also at ETH Zurich, took a different approach. They utilized a much simpler model of Earth's total energy budget and ran the model many thousands of times, using different combinations of a few crucial parameters that contribute to the energy budget. These included global values for incoming shortwave radiation from the Sun, solar energy leaving Earth, heat absorbed by the oceans and climate-feedback effects (such as reduced snow cover, which amplifies warming by exposing darker surfaces that absorb more heat).
\end{abstract}

By using the combinations that best matched the observed surface warming and ocean heat uptake, the authors then ran the soconstrained model with each energy parameter individually. This enabled them to estimate the contribution of $\mathrm{CO}_{2}$ and other climatechange agents to the observed temperature change. Their study was greatly assisted by a 2009 analysis ${ }^{2}$ of observed changes since 1950 in Earth's energy balance, says Knutti.

Knutti and Huber found that greenhouse gases contributed $0.6-1.1^{\circ} \mathrm{C}$ to the warming observed since the mid-twentieth century, with the most statistically likely value being a contribution of about $0.85^{\circ} \mathrm{C}$. Around half of that contribution from greenhouse gases -0.45 ${ }^{\circ} \mathrm{C}$ - was offset by the cooling effects of aerosols. These directly influence Earth's climate by scattering light; they also have indirect climate effects through their interactions with clouds.

The authors calculated a net warming value of around $0.5^{\circ} \mathrm{C}$ since the $1950 \mathrm{~s}$, which is very close to the actual temperature rise of $0.55^{\circ} \mathrm{C}$ observed over that period. Changes in solar radiation - a hypothesis for global warming proffered by many climate sceptics — contributed no more than around $0.07^{\circ} \mathrm{C}$ to the recent warming, the study finds.

To test whether recent warming might just be down to a random swing in Earth's unstable climate - another theory favoured by sceptics - Knutti and Huber conducted a series of control runs of different climate models without including the effects of the energy- 
budget parameters. But even if climate variability were three times greater than that estimated by state-of-the-art models, it is extremely unlikely to have produced a warming trend as pronounced as that observed in the real world, they found.

"This tightens estimates of past responses," says Gabriele Hegerl, a climate scientist at the University of Edinburgh, UK, "And it should also lead to predictions of future climate change that are grounded in the kind of changes already being observed."

For more breaking news about climate change, read the latest research showing 'How the financial crisis barely dented carbon emissions'.

Nature | doi:10.1038/nature.2011.9538

\section{References}

1. Huber, M. \& Knutti, R. Nature Geoscience advance online publication http://dx.doi.org/10.1038/ngeo1327 (2011).

2. Murphy, D. M. et al. J. Geophys. Res. http://dx.doi.org/10.1029/2009JD012105 114, D17107 (2009). 